\title{
HISTOPATHOLOGICAL ANALYSIS OF BIOPSY SPECIMENS OF ONE YEAR AT SHREE BIRENDRA HOSPITAL
}

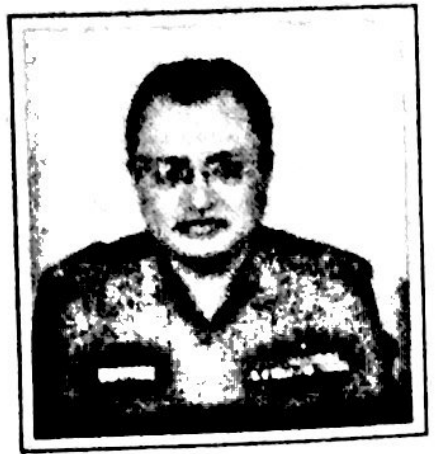

Let. Col. Dr. Rajesh Panth, MD Head of Department of Pathology

Diagrammatic and tabular presentation of diagnoses of biopsy specimens received in one year helps us to refine our knowledge about the incidence and prevalence of various lesions for which histopathological examination is requested. The following is a humble attempt to analyze a total of 1296 lesions diagnosed at the Army Hospital in the year 2060 B.S.

Most frequently biopsied organs:

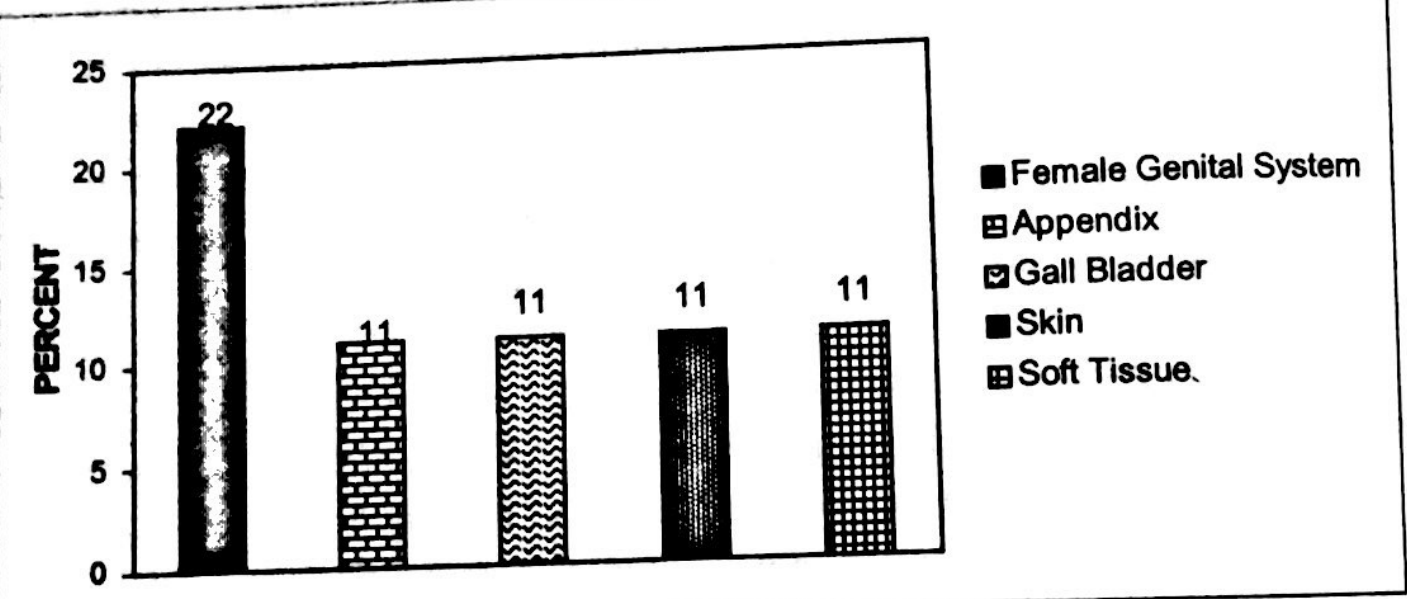

Skin (145):

\section{Lesions}

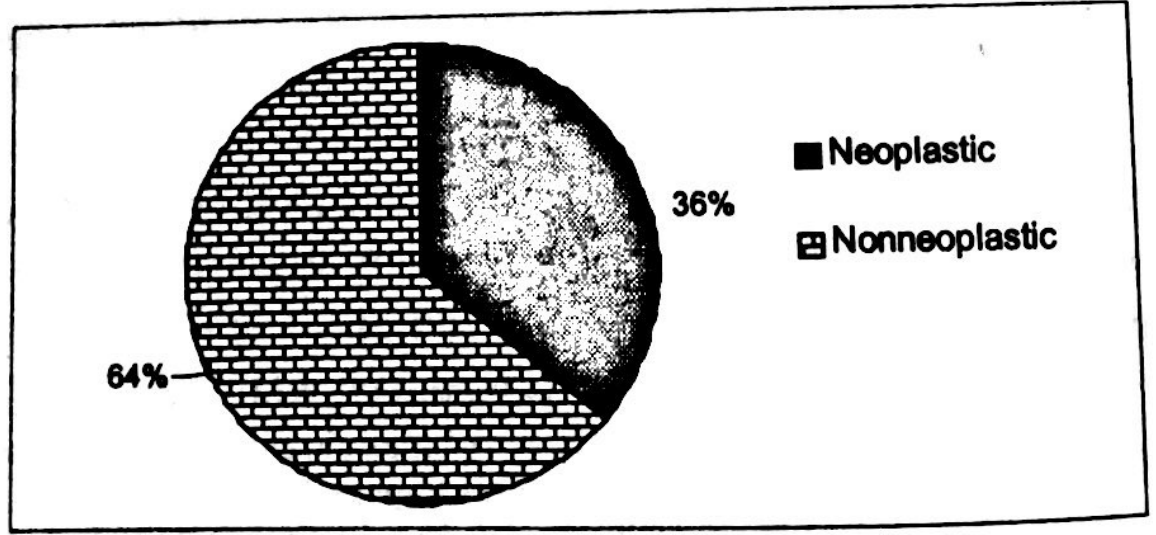


Noneoplastic Lesions

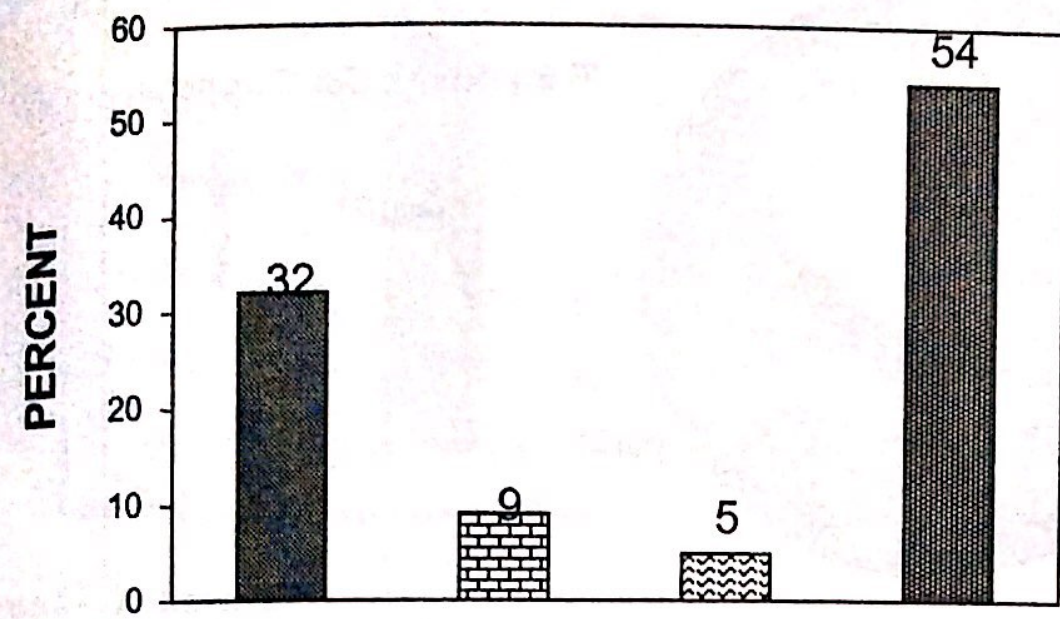

뭄 Cyst (Epidermoid

\& Pilar)

تChronic Dermatitis

国Leprosy

圈Others

\section{Tumours}

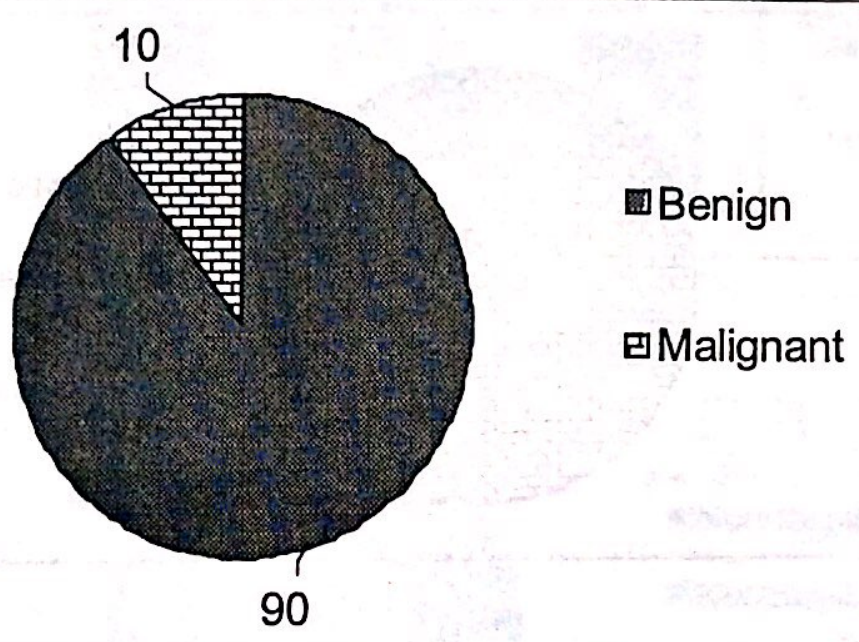

\section{Benign Tumours}

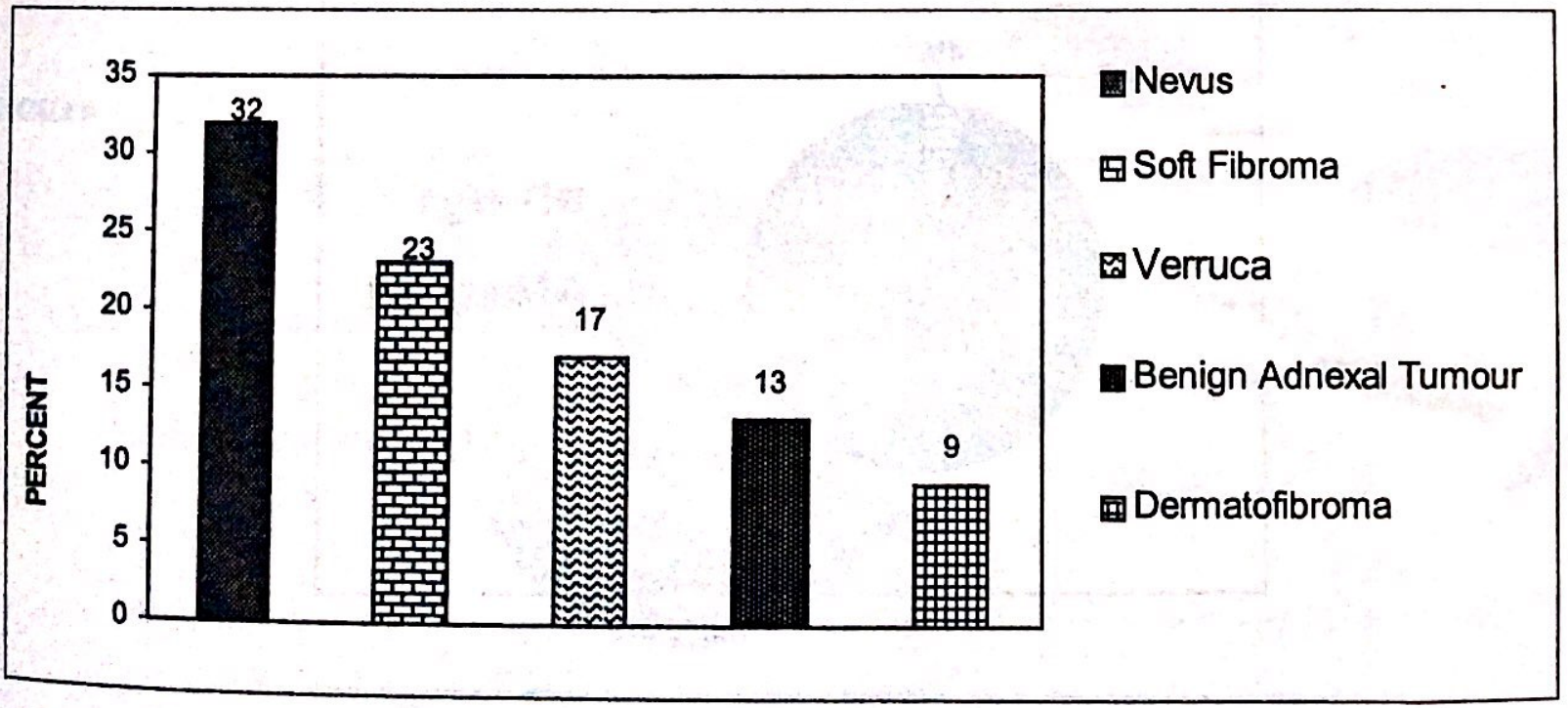




$$
\begin{aligned}
& 0 \\
& 0= \\
& 0=
\end{aligned}
$$


Benign Tumours

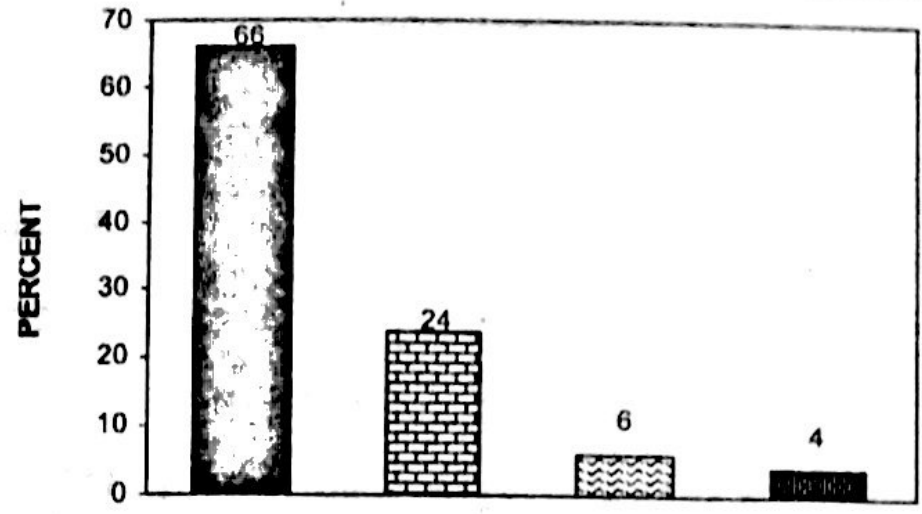

- Adipocytic

ஐVascular

QNeural

- Fibrous

\section{Malignant Tumours}

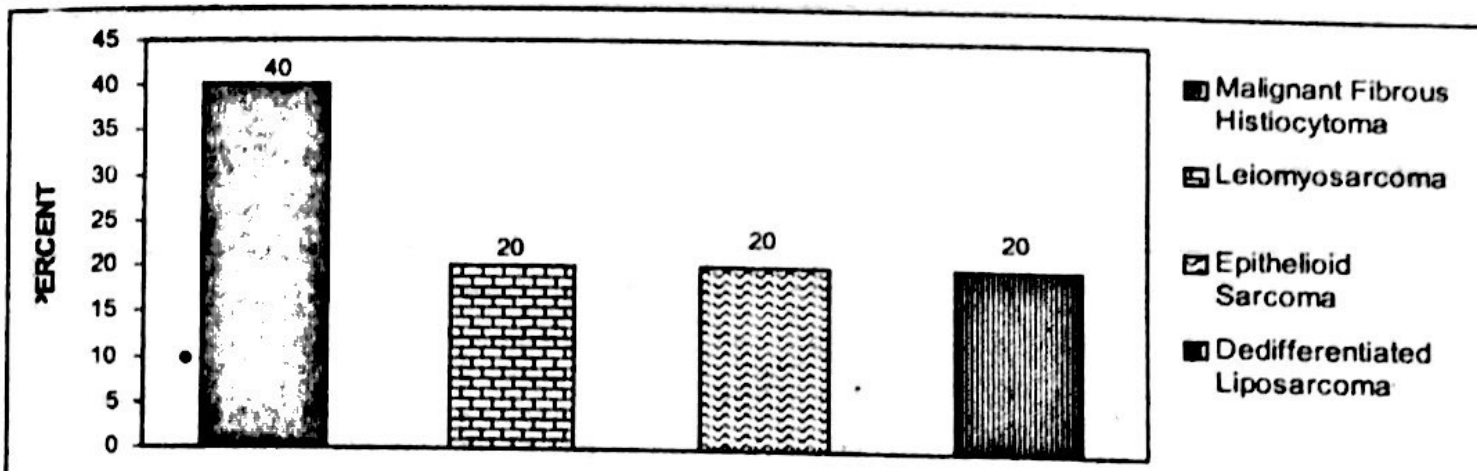

\section{Bone and Joint (25)}

\section{Lesions}

\section{Tumours}
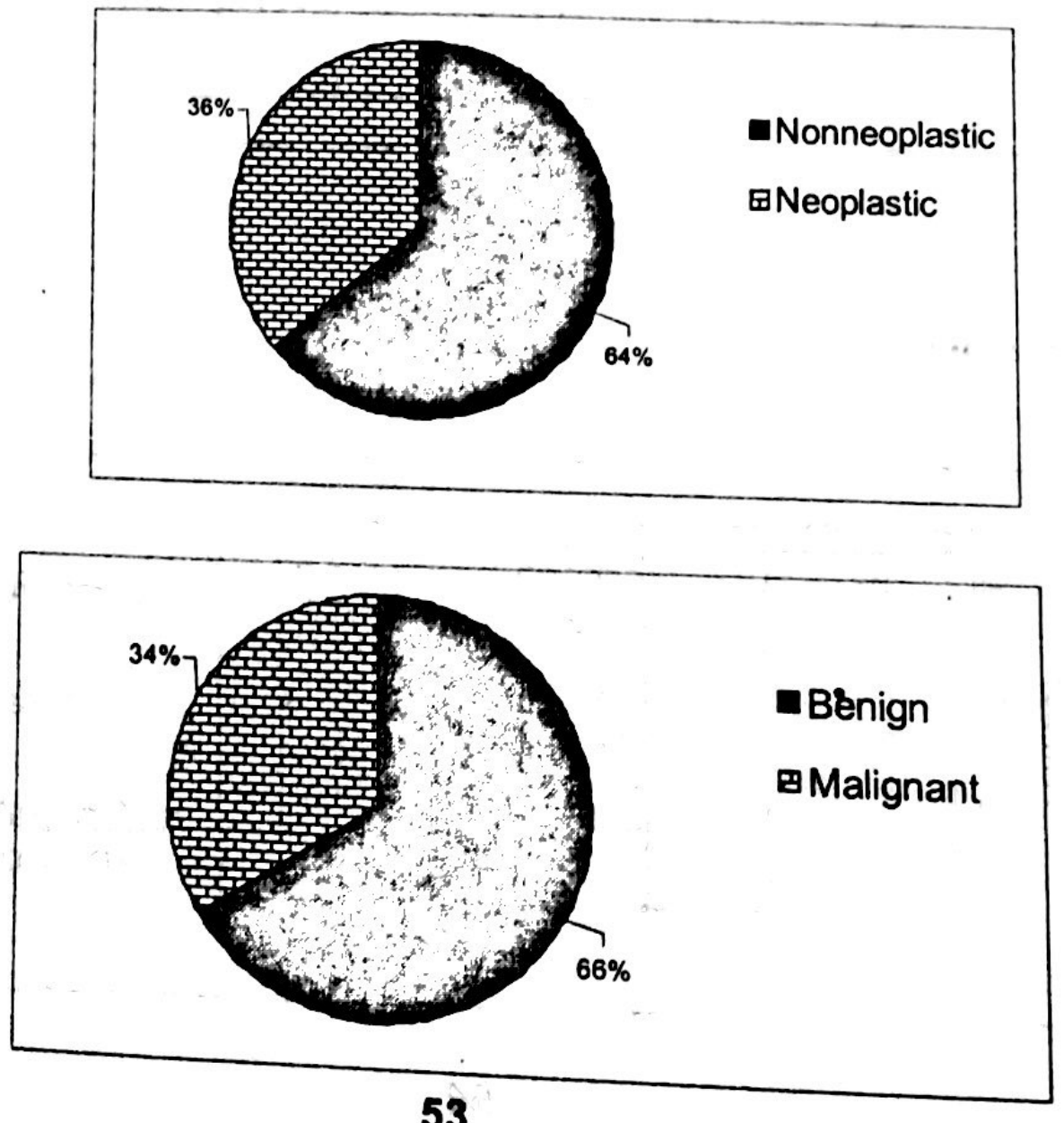


\section{Nonneoplastic Lesions}

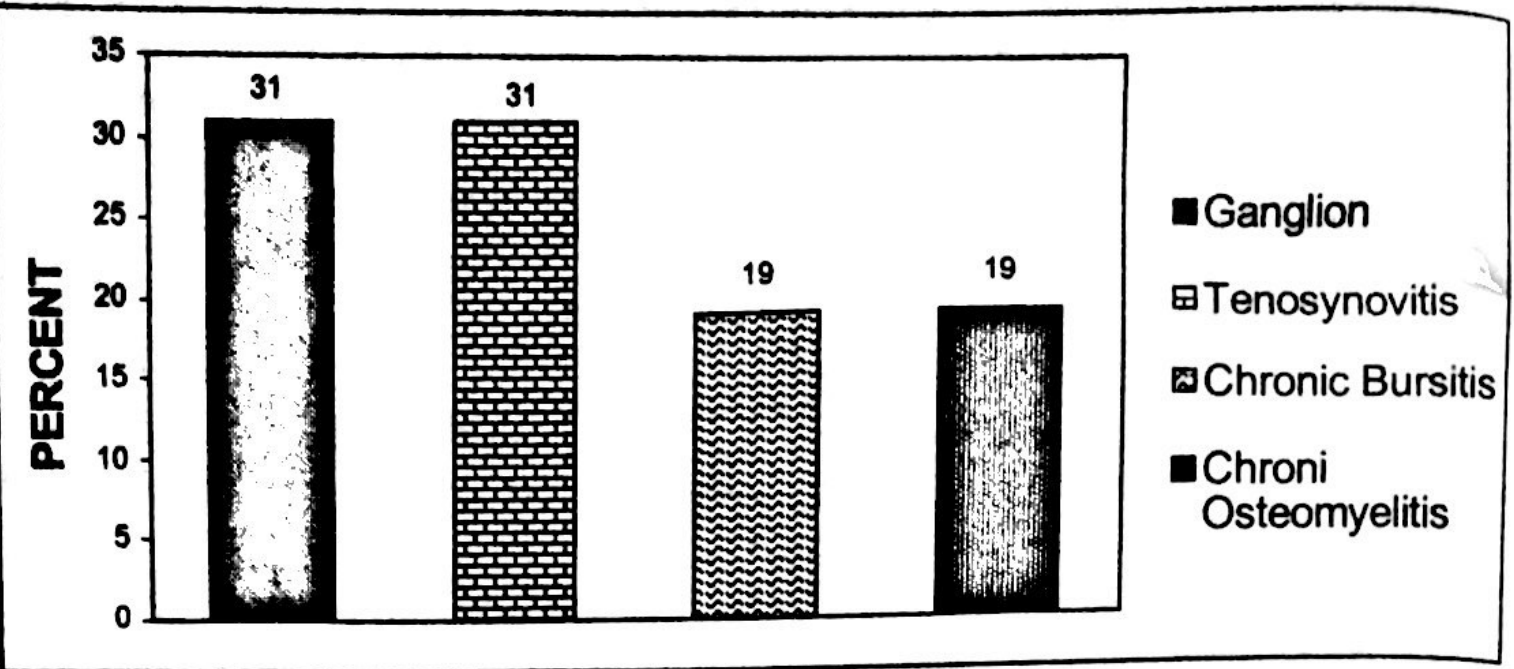

\section{Benign Tumours}

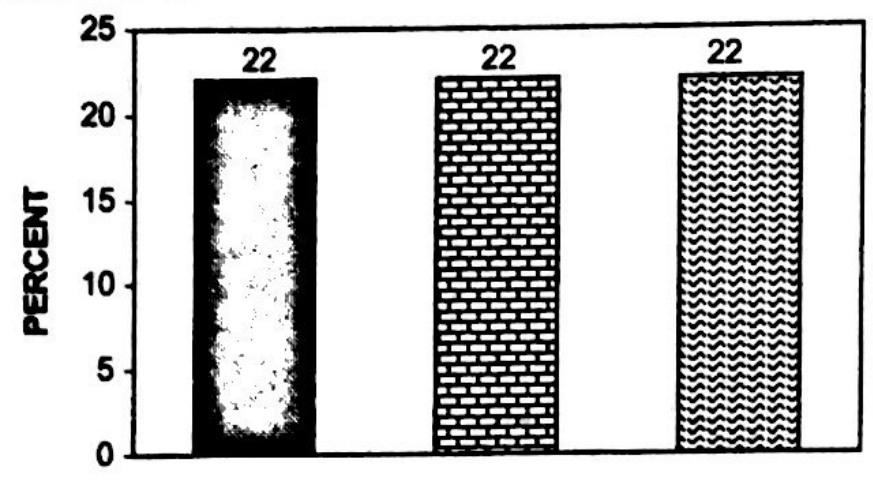

- Osteochondroma

ت

순iant Cell

Tumour

\section{Malignant Tumours}

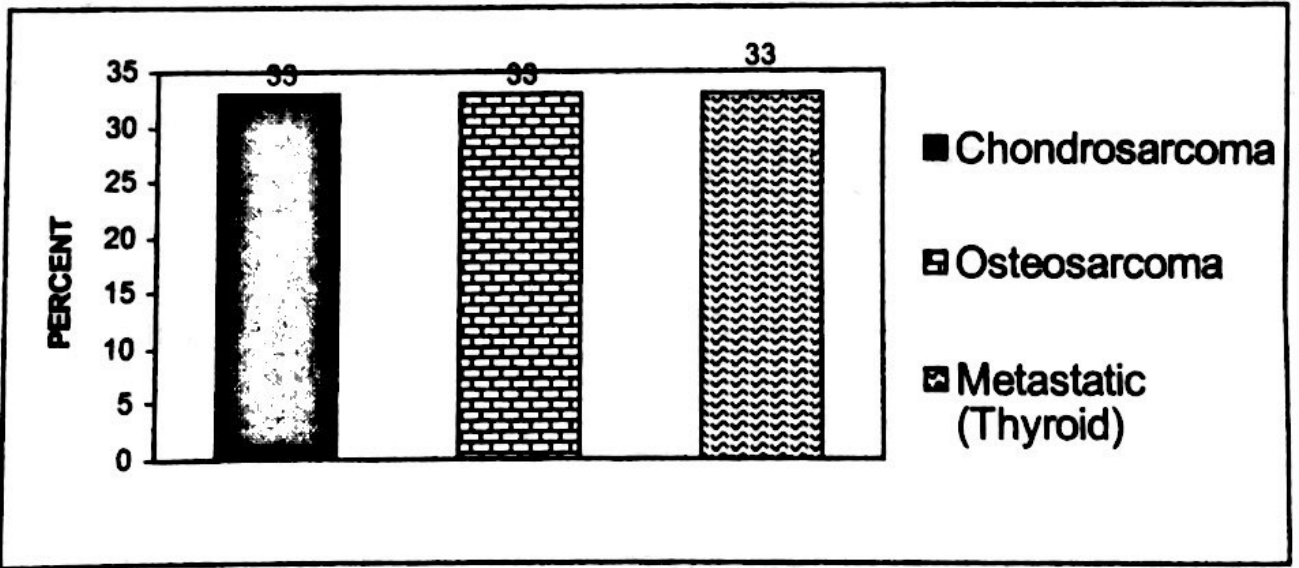


Oronasal Cavity (33)

Lesions

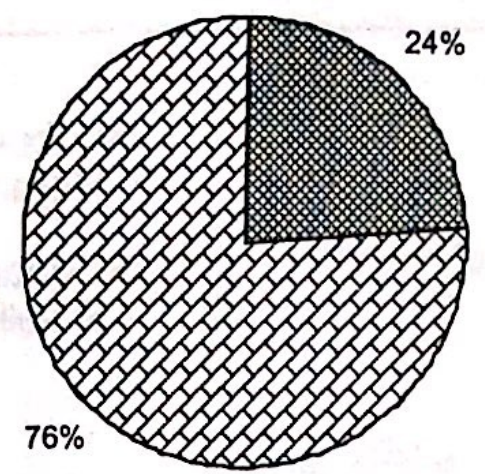

Neoplastic

囚Nonneoplastic

Nonneoplastic Lesions

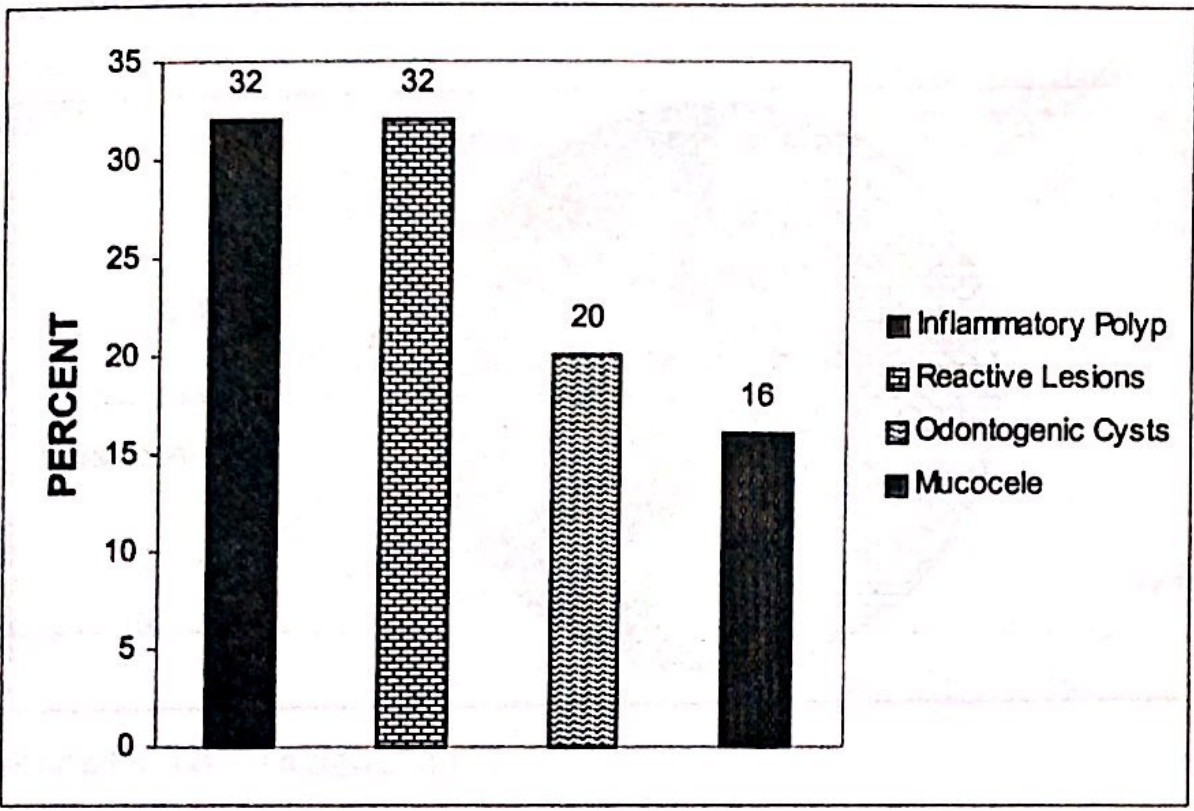

Tumours

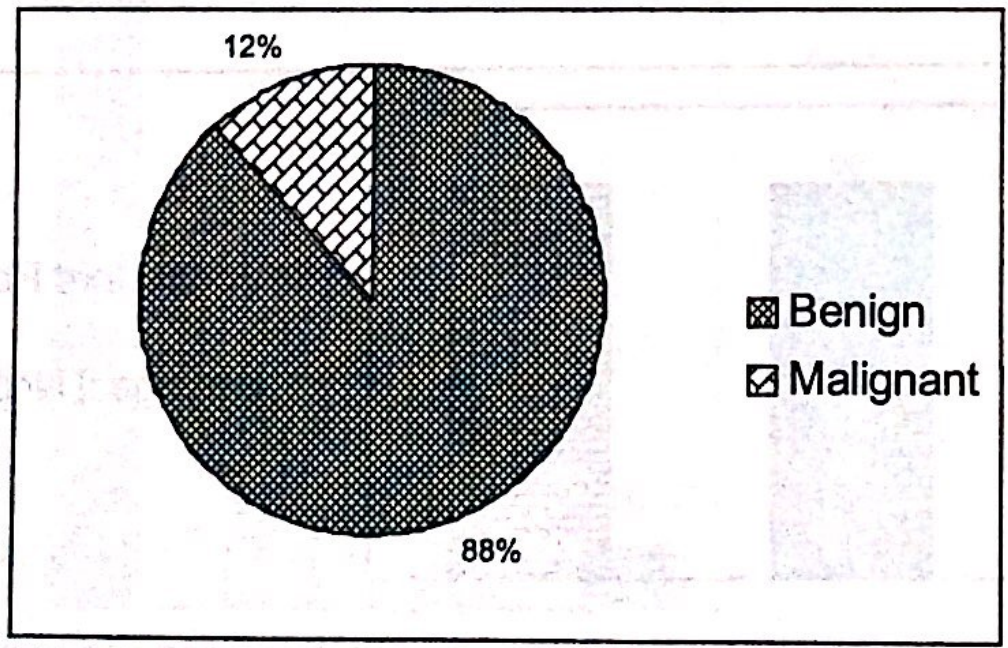




\section{Benign Tumours}

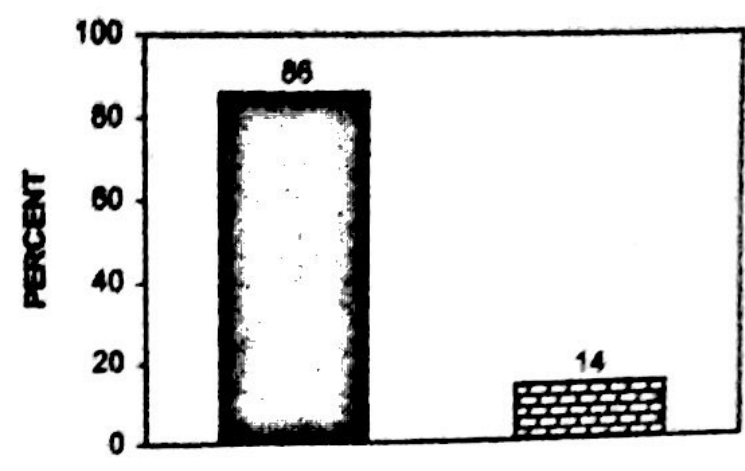

- Lobular

Hemangioma

ESquamous

Papilioma

Larnyx (11)

\section{Leslons}

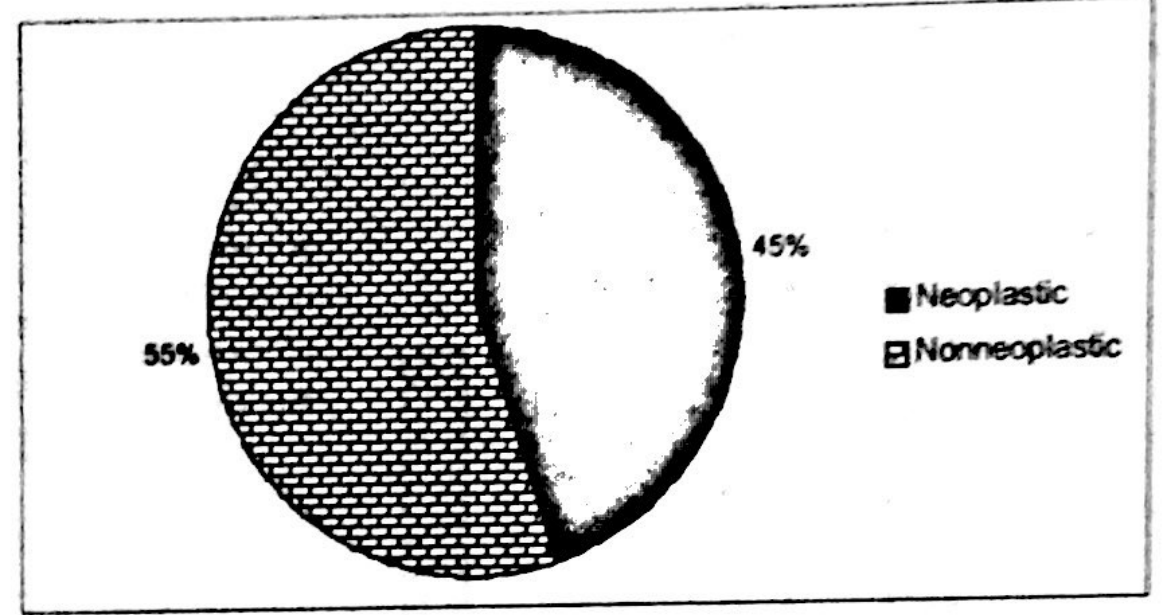

Nonneoplastic Lesions

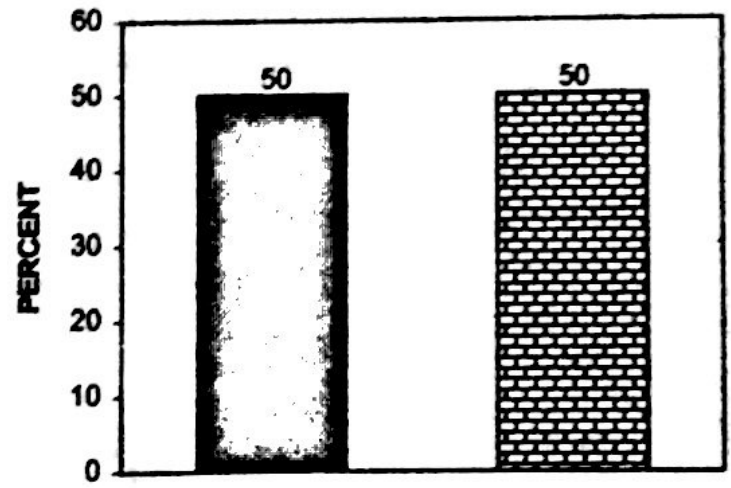

- Vocal Cord Polyp

ELaryngeal Nodule 


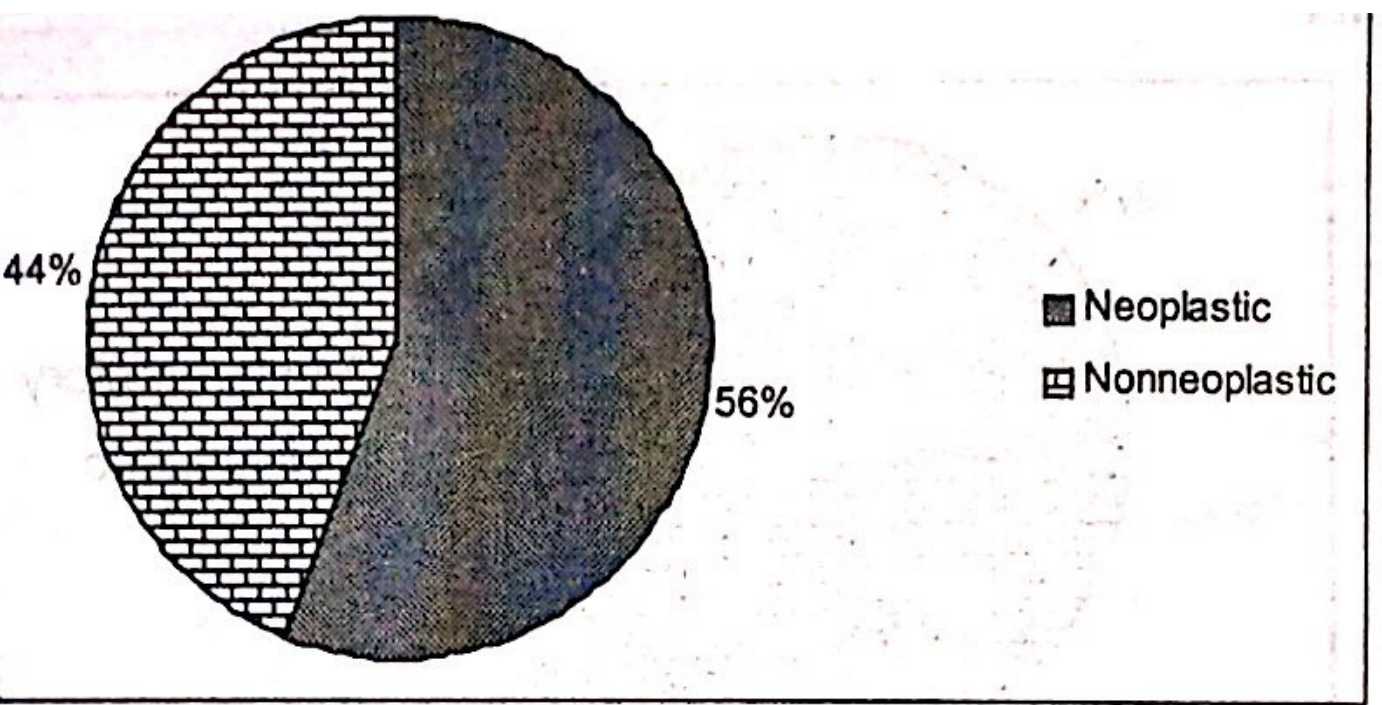

\section{All Malignant)}

35

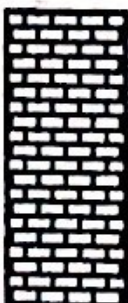

뭄 Squamous Cell Carcinoma

巴Small Cell Carcinoma

田 Adenocarcinoma

nonsmall Cell Carcinoma 


\section{Endoscople Blopsy (99)}

\section{Sltes}

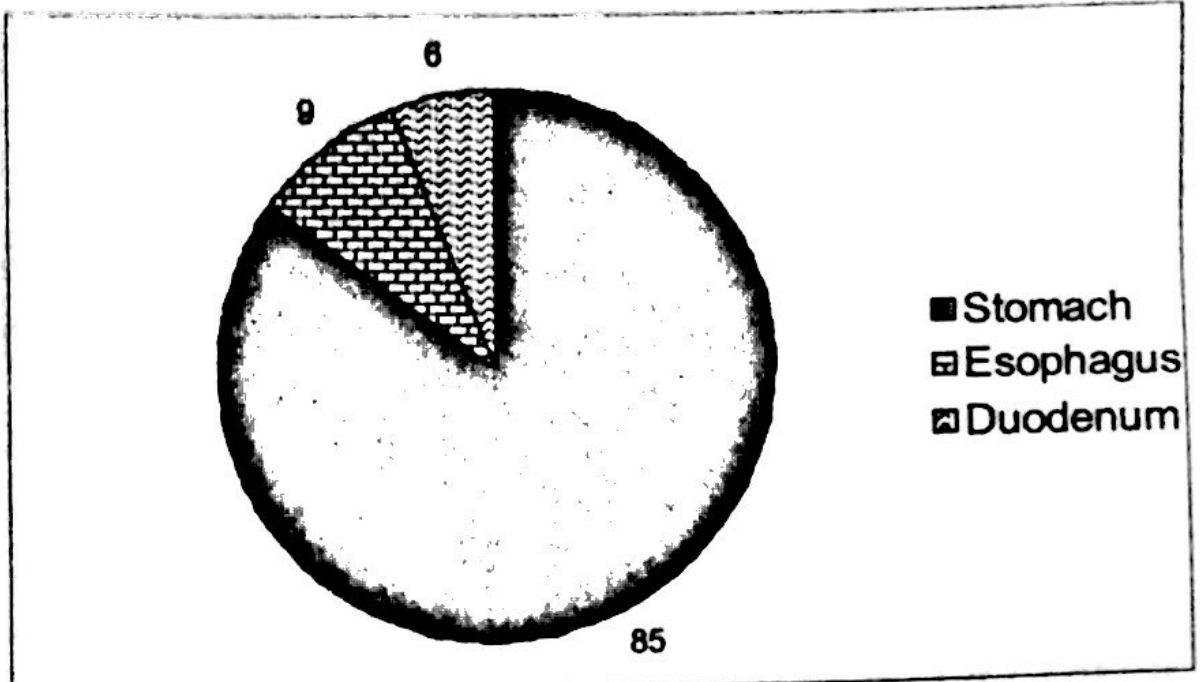

Nature of Lesions

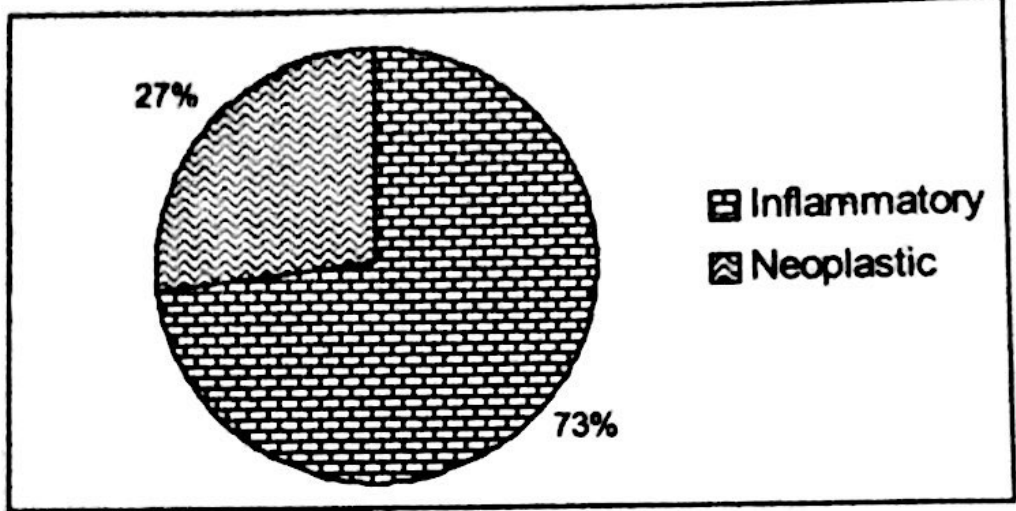

Carcinoma as Percent in Involved Sites

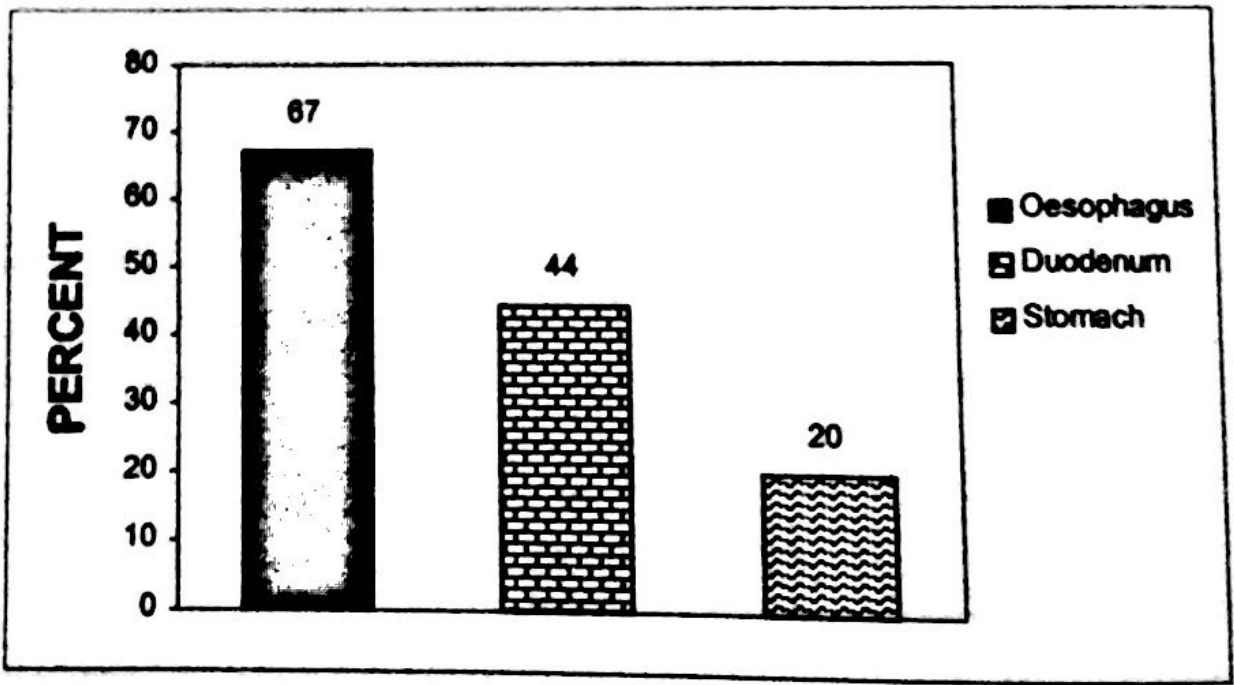


Site of Chronic Gastristis

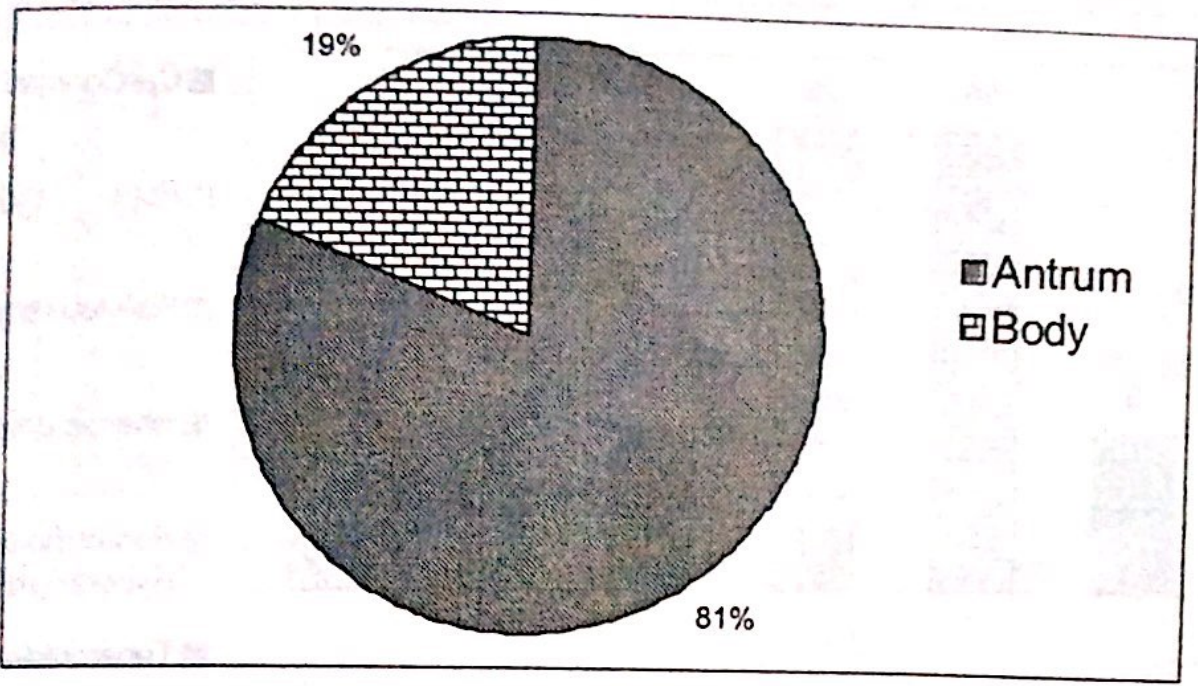

Helicobacter Pylori in Gastritis

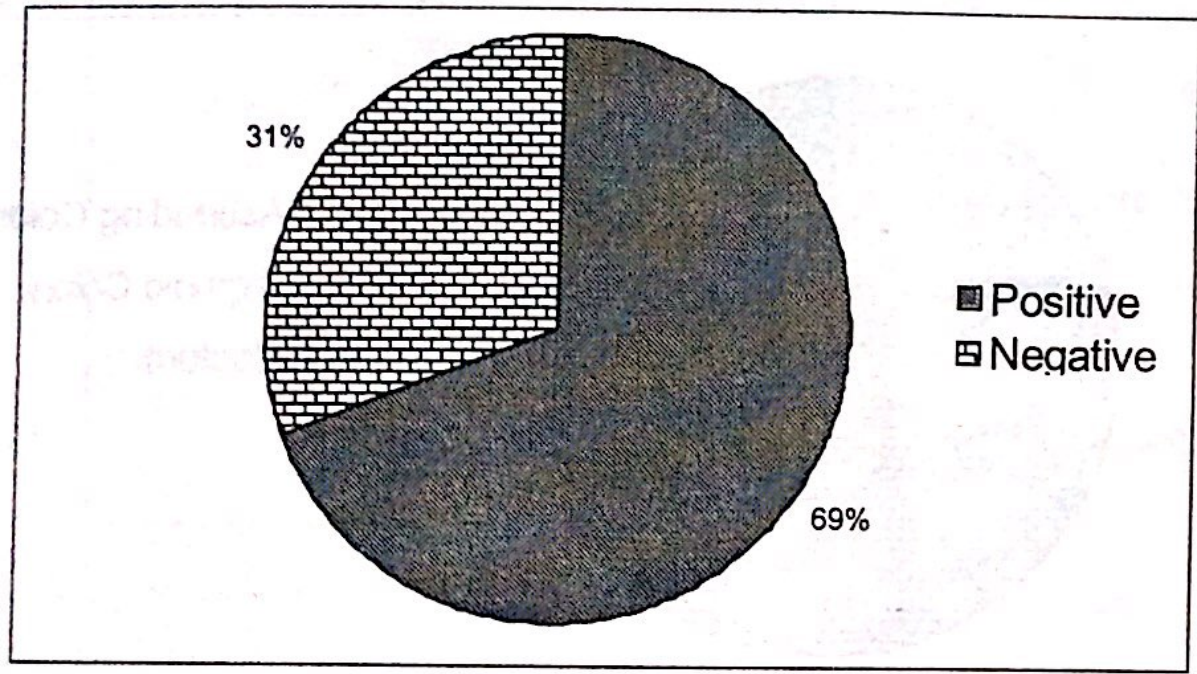

Types of Inflammatory Lesions in Stomach

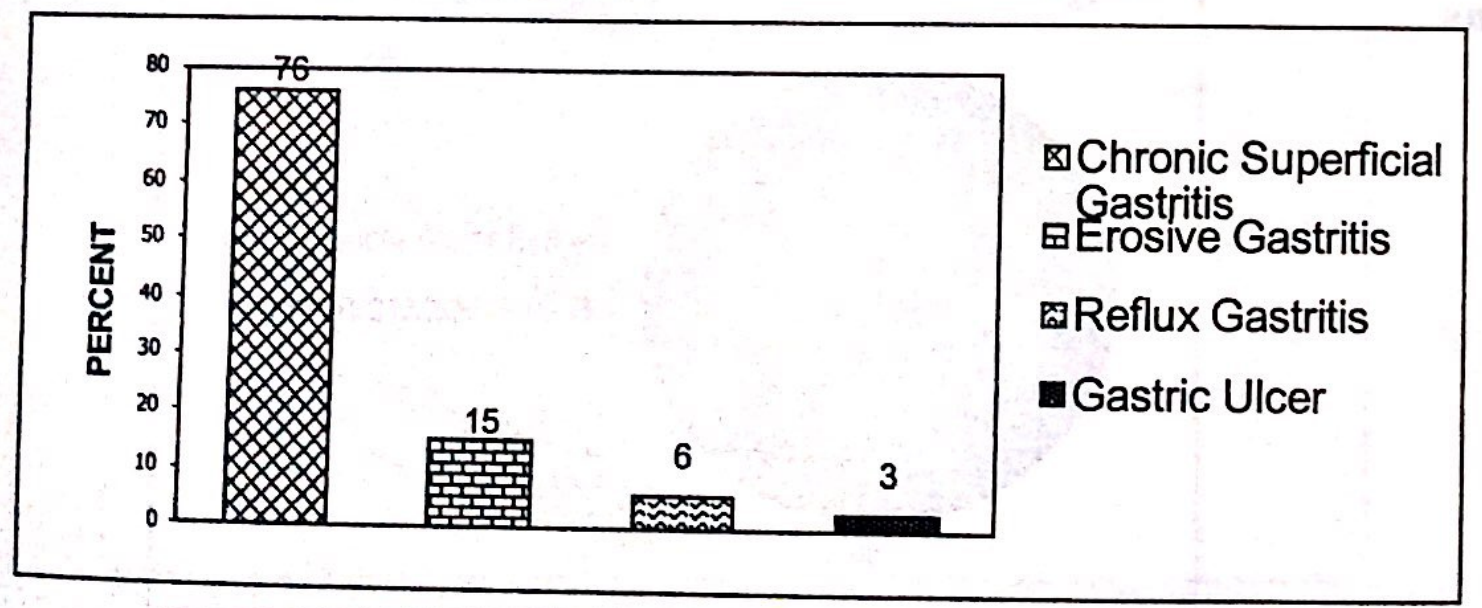




\section{Intestines (35)}

\section{Lesions}

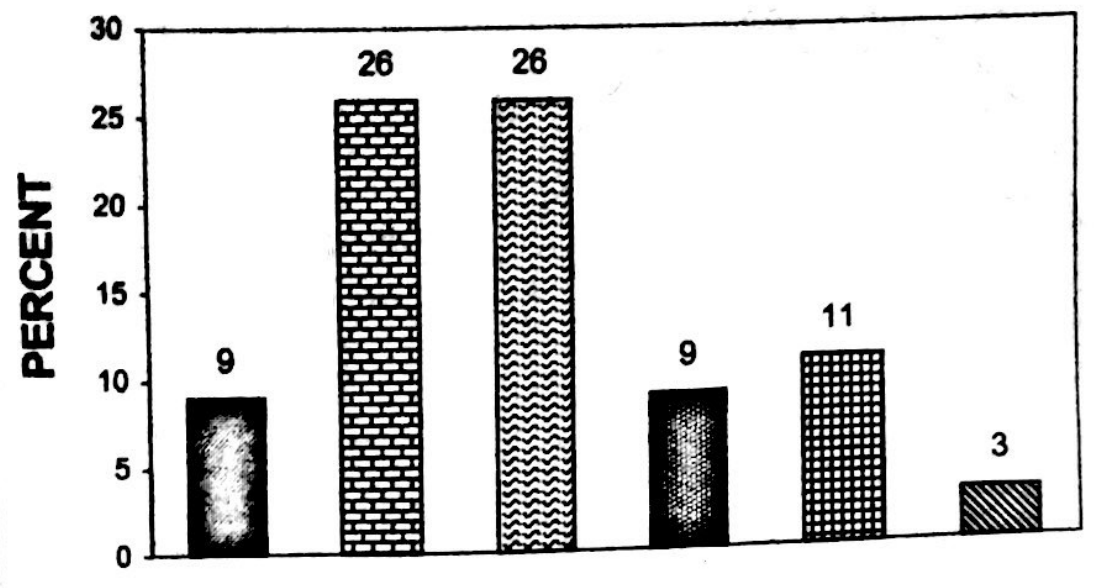

Carcinoma

巴Polyp

Fistulous tract

Ishemic bowel Disease

田Hemorrhoids\&

Hypertrophied Anal Papille

NTuberculosis

\section{Intestines (35)}

\section{Lesions}

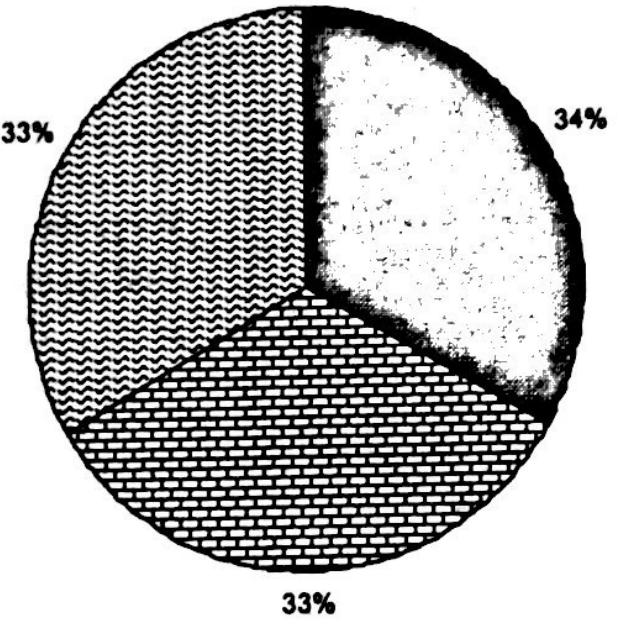

-Ascending Colon घSigmoid Colon هRectum

\section{Gall Bladder (144)}

\section{Lesions}

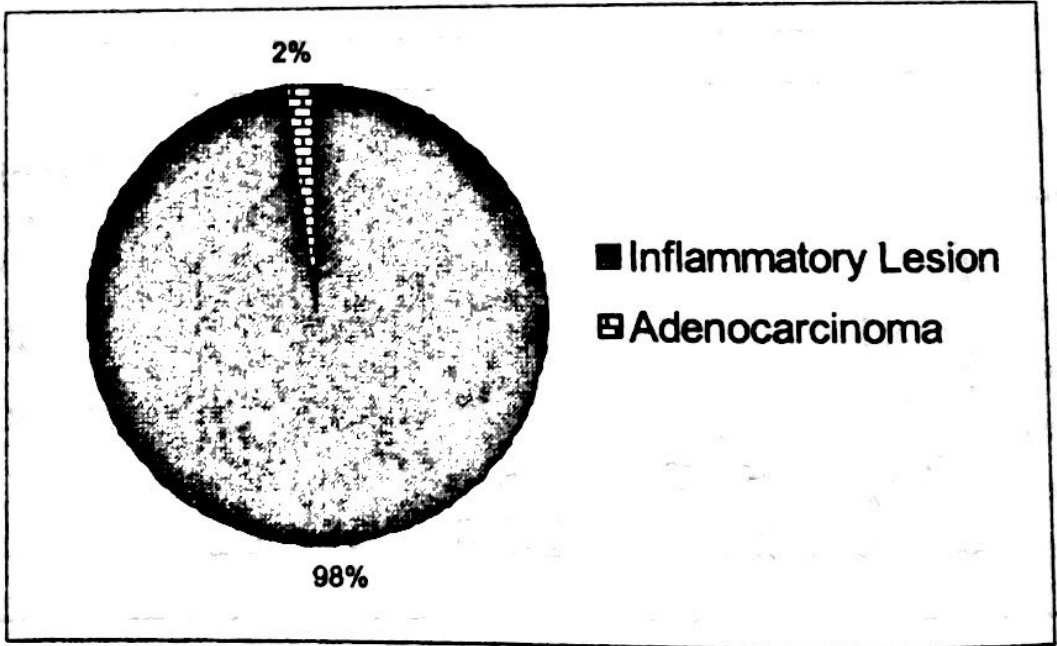


Types of Cholecystitis

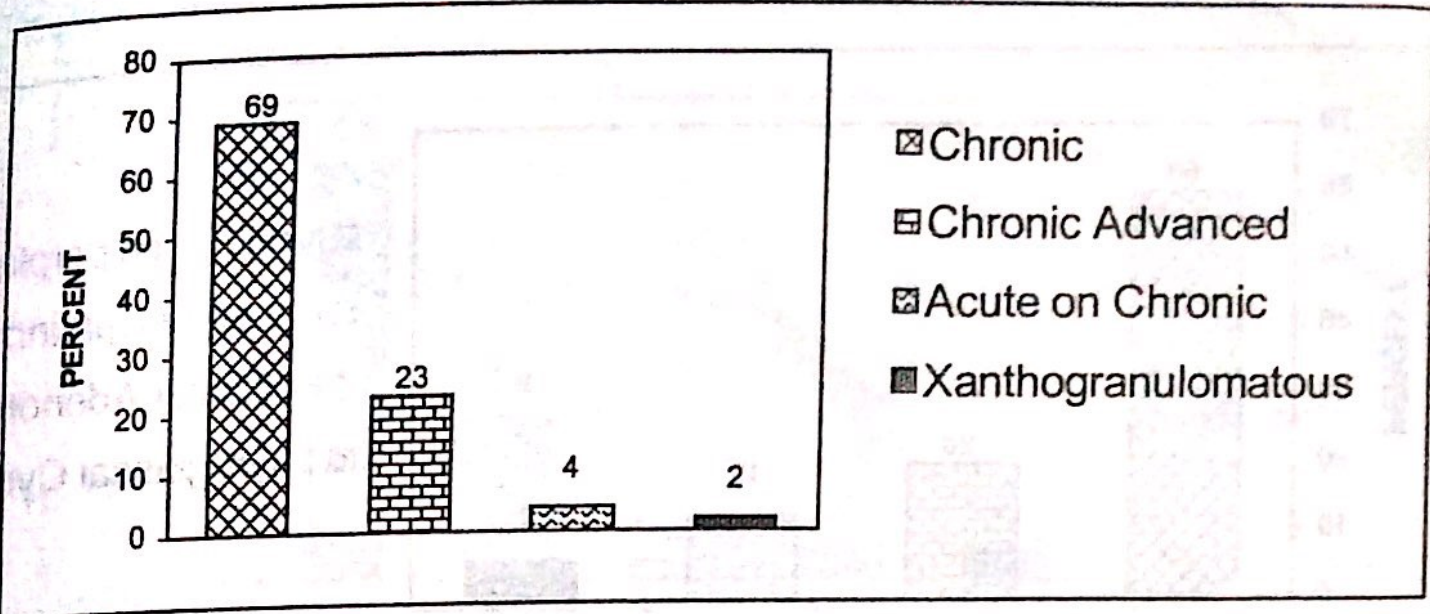

\section{Appendix (146)}

\section{Lesions}

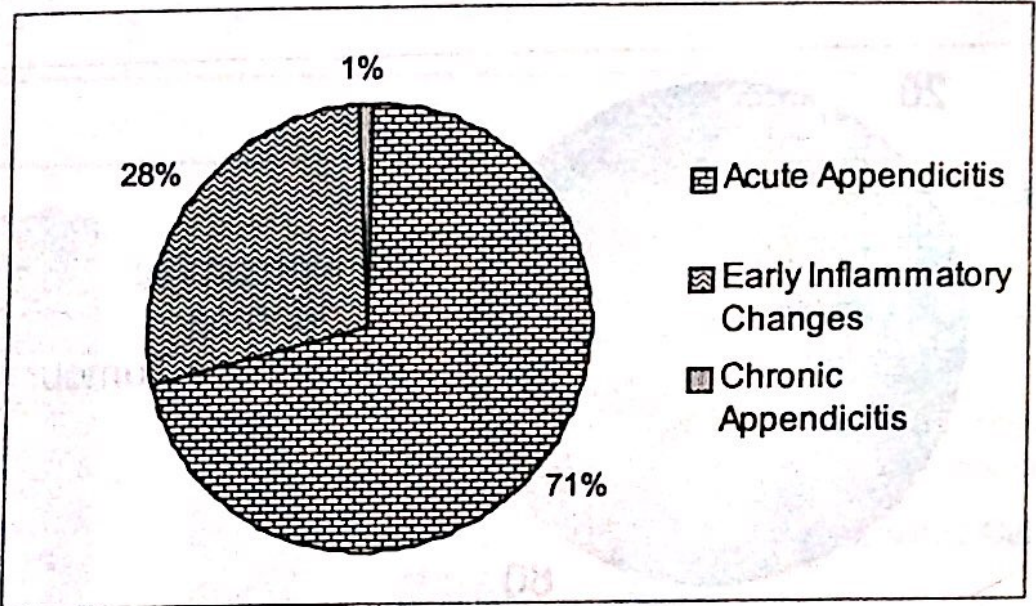

\section{Thyroid (15)}

\section{Lesions}

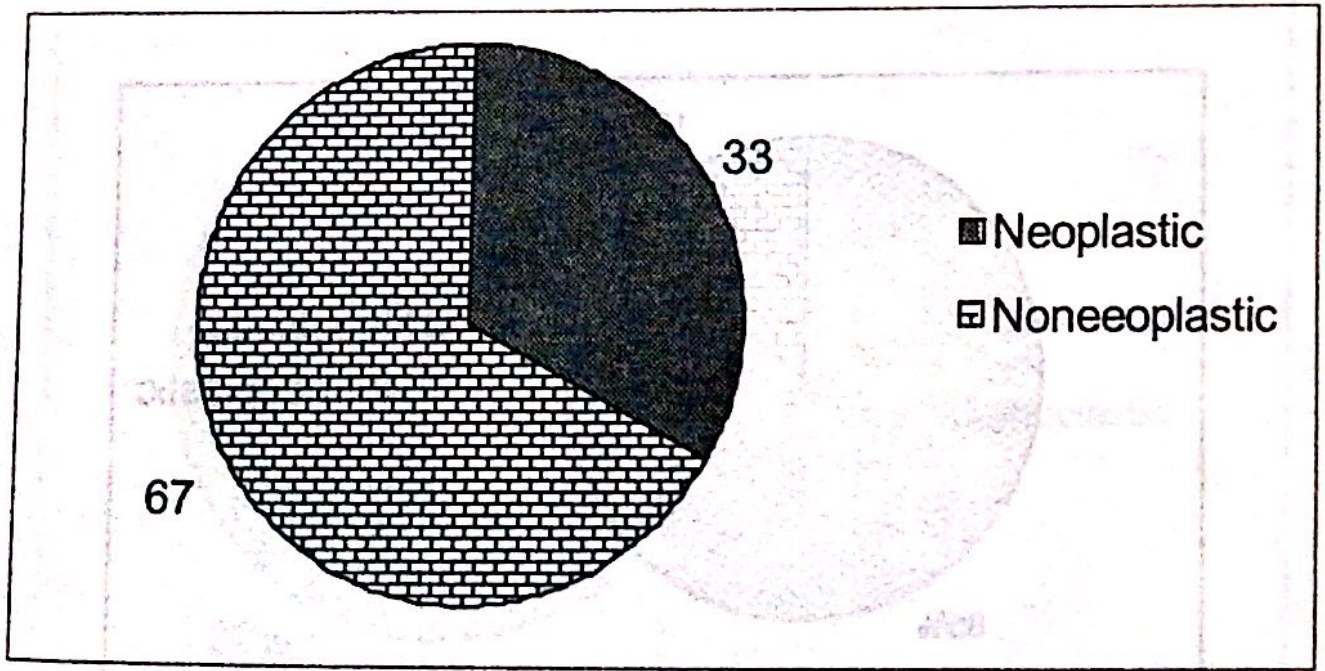




\section{Lesions}

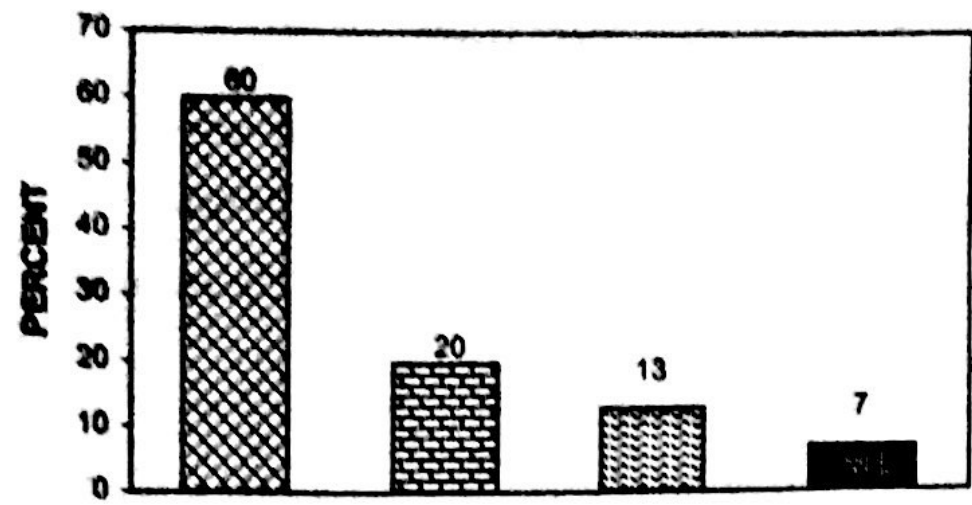

هNodular Hyperplasia EPapillary Carcinma ఐFollicular Adenoma - Thyroglassal Cyst

Salivary Gland (5)

\section{Lesions}

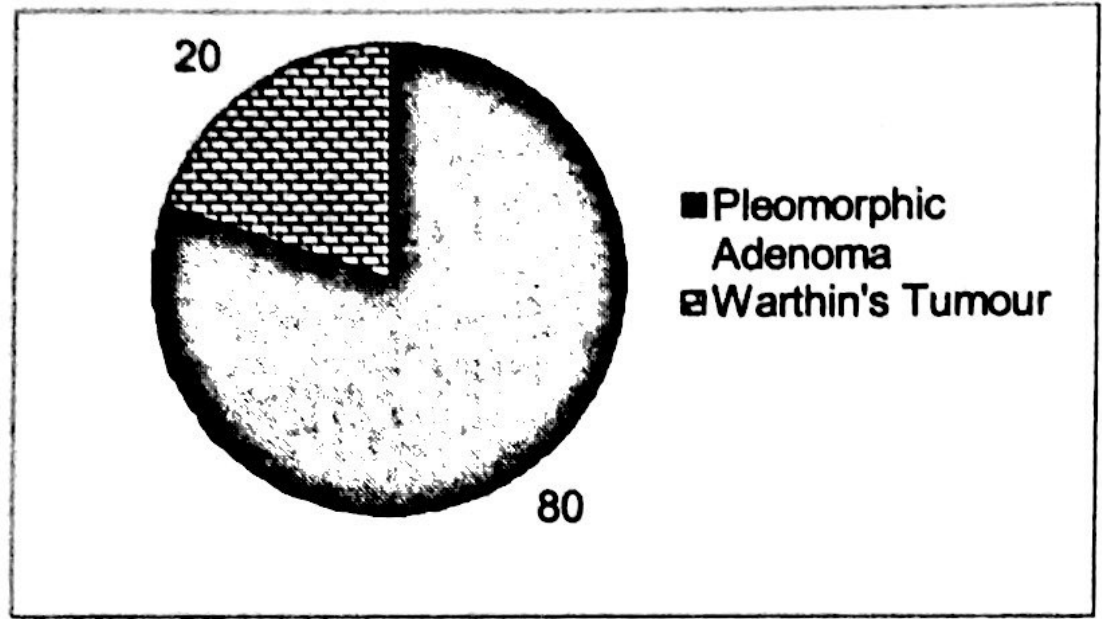

\section{Lymph Nodes (33)}

\section{Lesions}

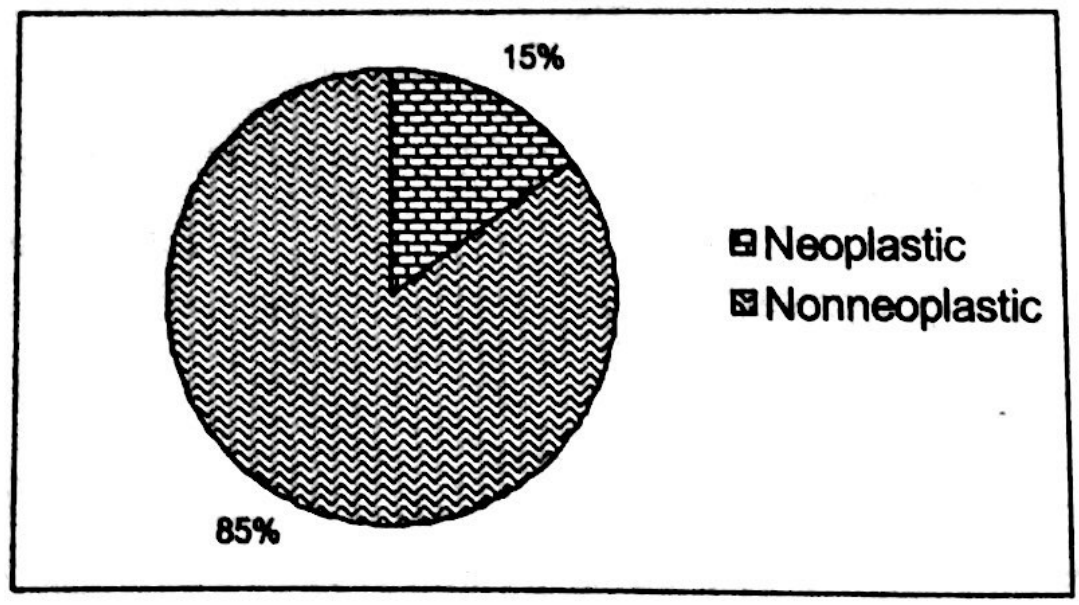


Lesions

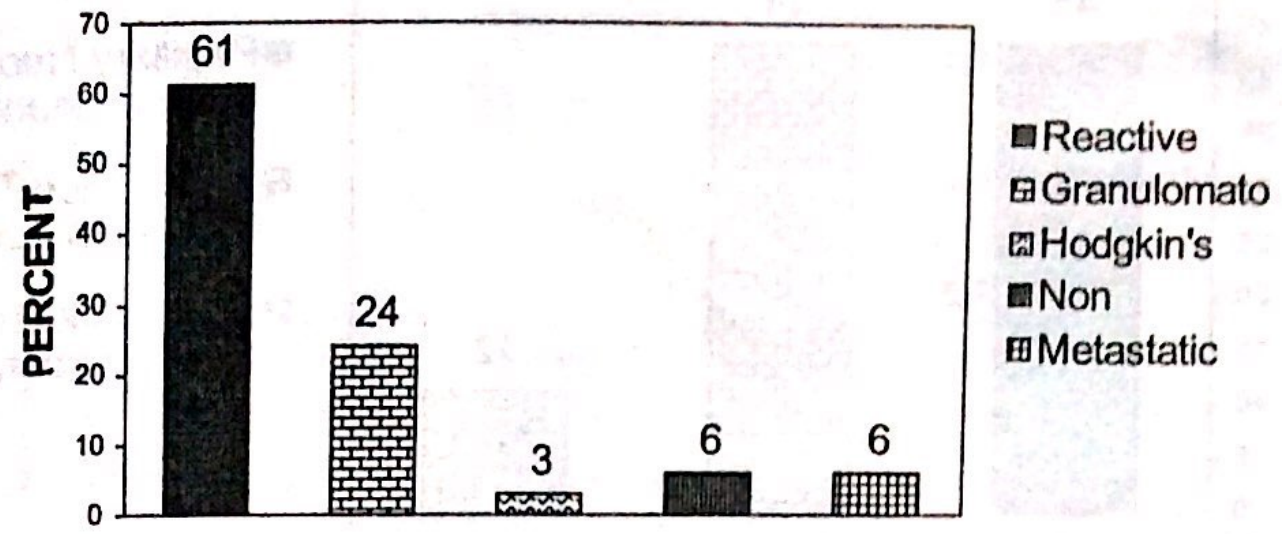

Kidney (5)

Lesions

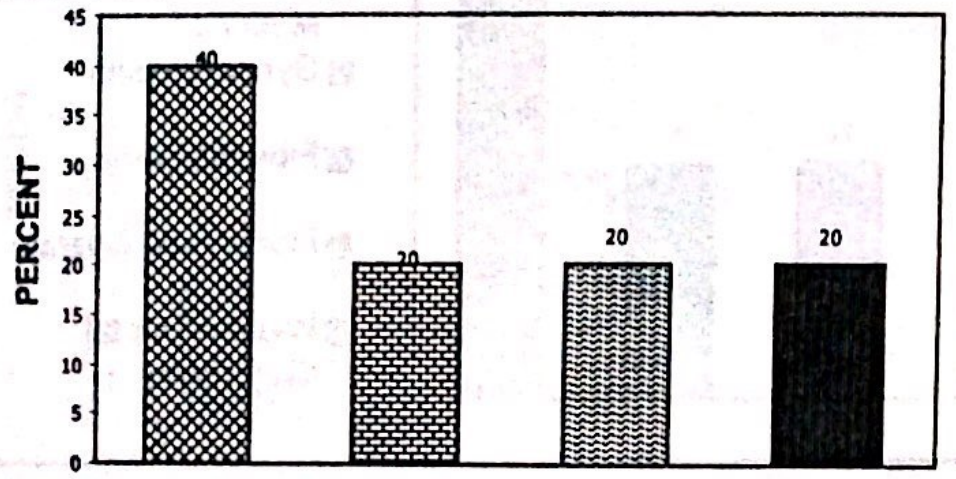

B Glomerulonephritis

国Polysystic Kidney Disease

图Hydronephrosis with Pyelonephritic Changes

Renal Cell Carcinoma

\section{Urinary Bladder (11)}

\section{Lesions}

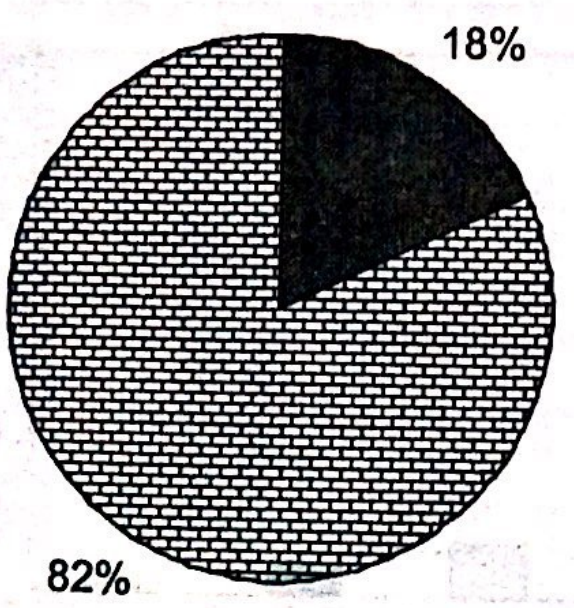

Inflammatory

円 Neoplastic 


\section{Neoplastic Lesions}

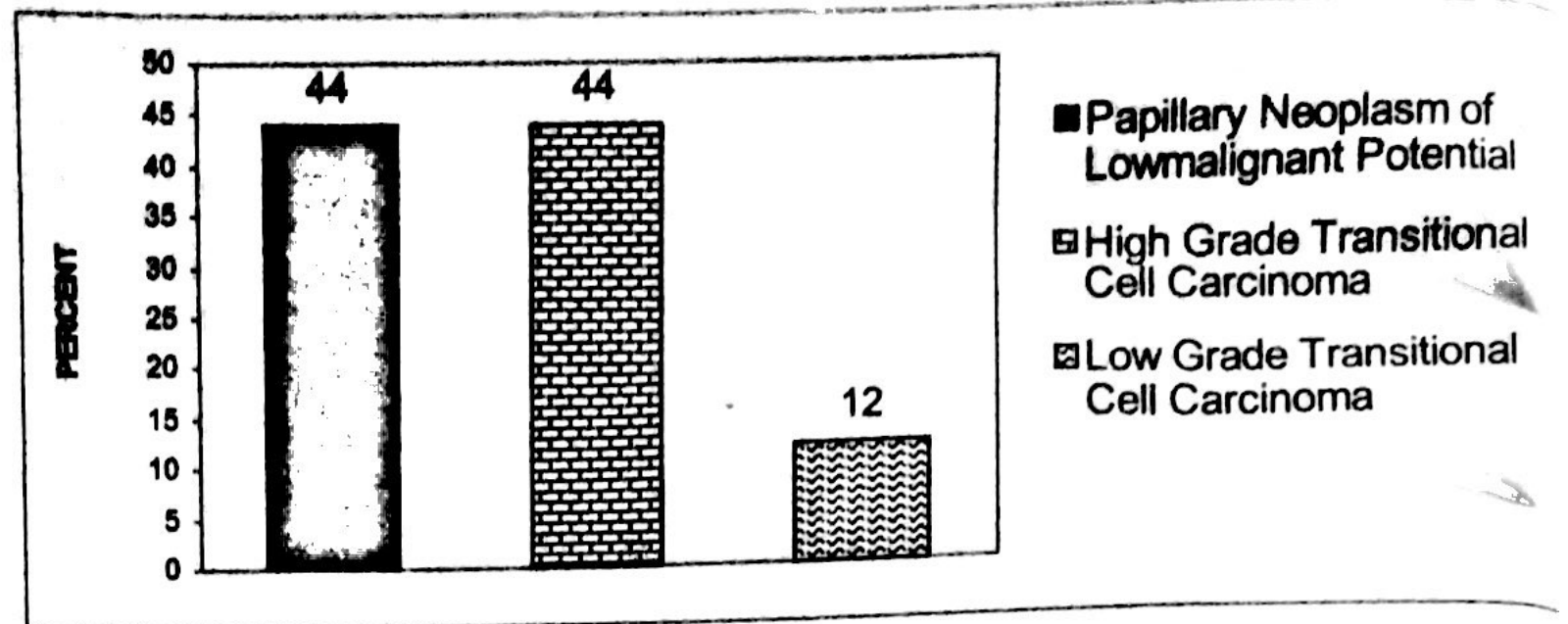

\section{Breast (14)}

\section{Lesions}

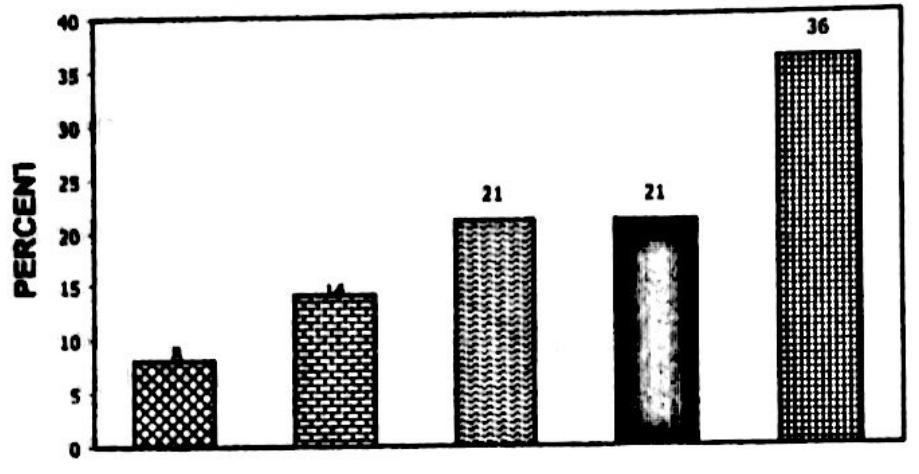

Chronic Granulomatous Mastitis GGnecomastia

由Fibroadenoma

Fibrocystic Change

田 Invasive Ductal

Carcinoma

\section{Male Genital System (72)}

\section{Biopsy Sites}

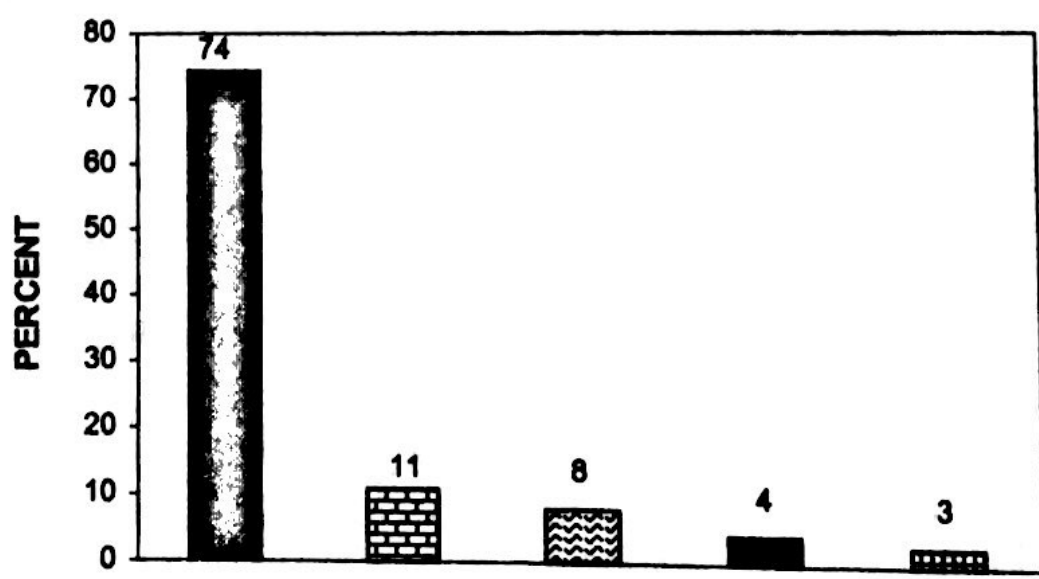

Prostate

QVas

Testis

-Penis

由Scrotum 
Commonest Lesions

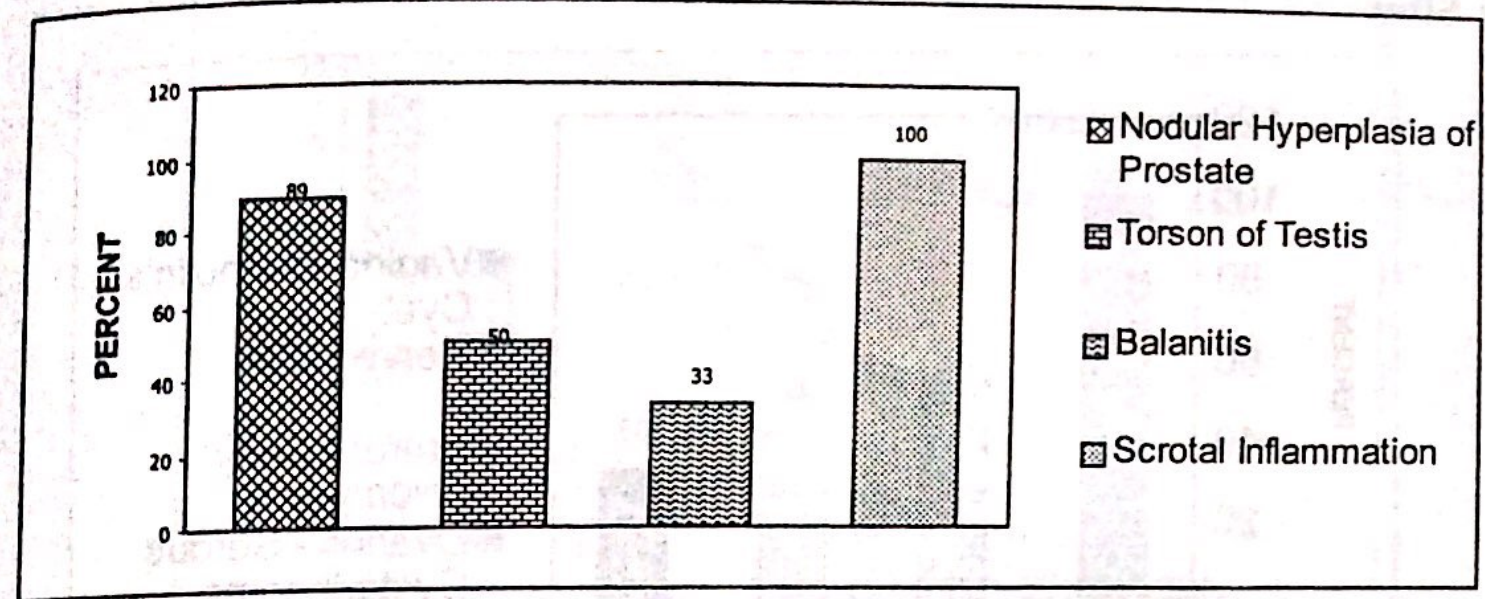

Neoplastic Lesions

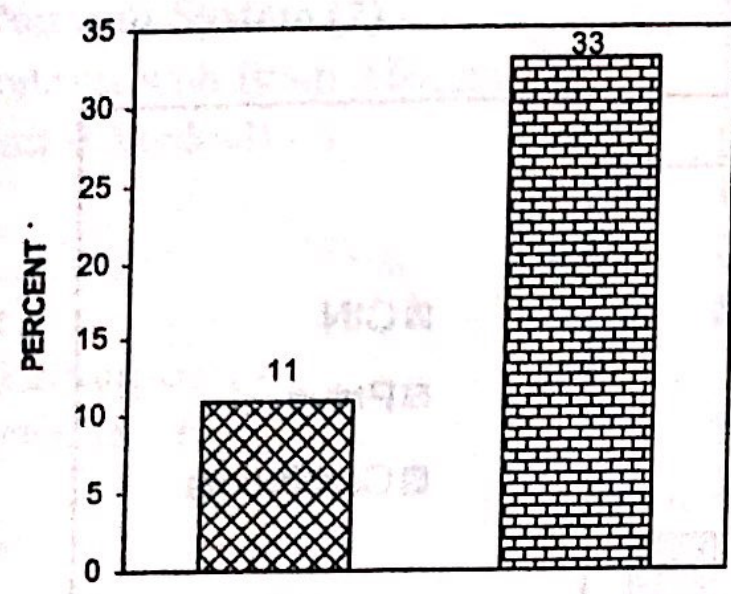

\PIN \& Carcinoma (Prostate) घGerm Cell Tumour (Testis)

\section{Female Genital System (289)}

\section{Biopsy Sites}

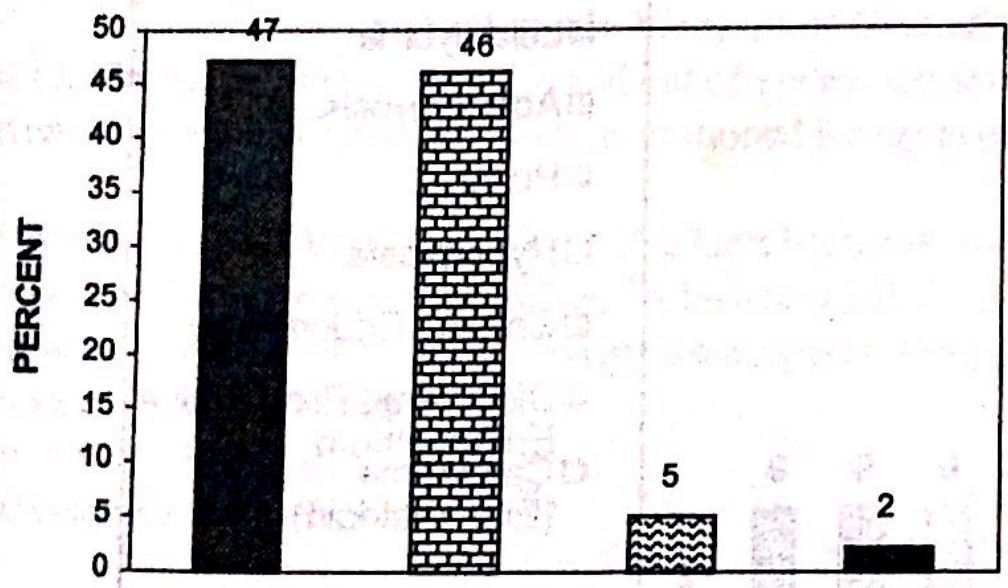

- Uterus (Body)

由Cervix

mOvaries

vagin 
Female Gevital System (289)

Blopsy Sites

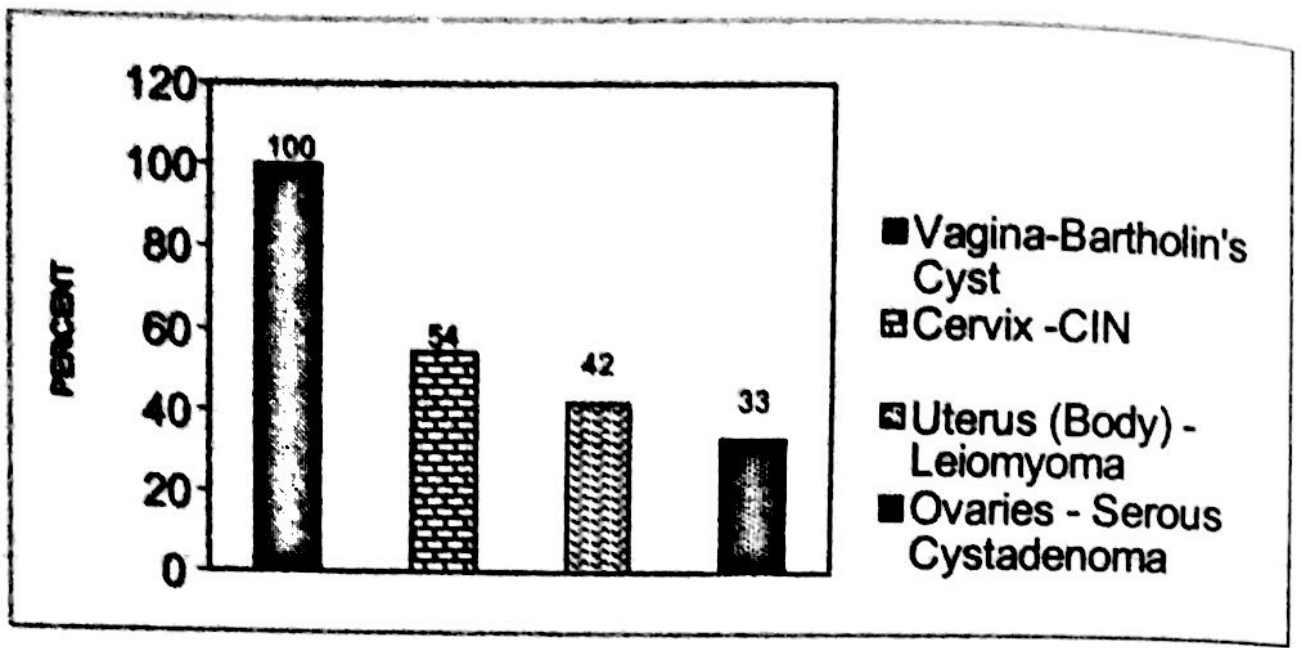

\section{Significant Lesions}

\section{Cervix}

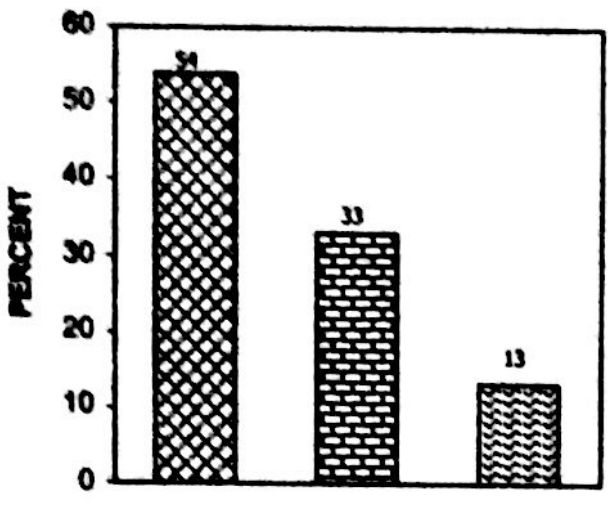

$\Delta \mathrm{CIN}$

BPolyp

- Carcinoma

\section{Uterus (Body)}

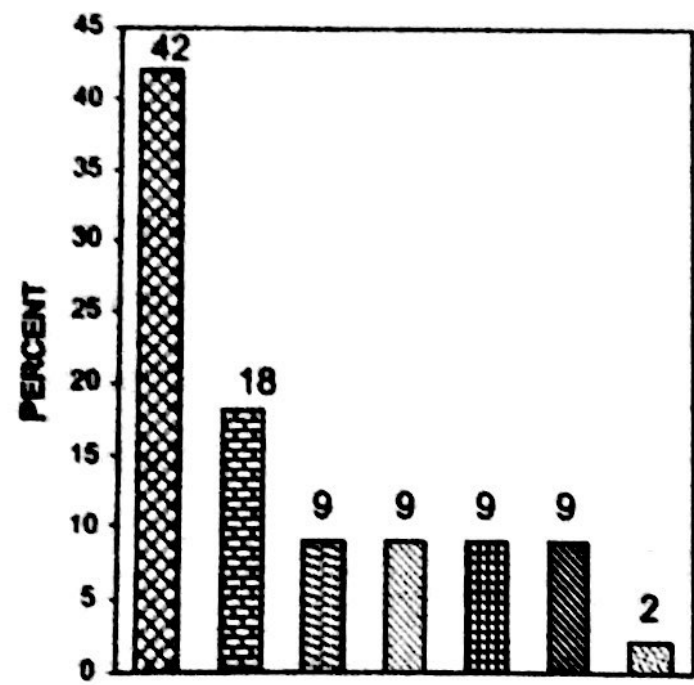

- LLeiomyoma $^{2}$

MAdenomyosis

EPolyp

هHyperplasia

由Chronic Endometritis

Disordered Proliferative Endometrium - Carcinoma

(Endometrioid) 
Ovaries

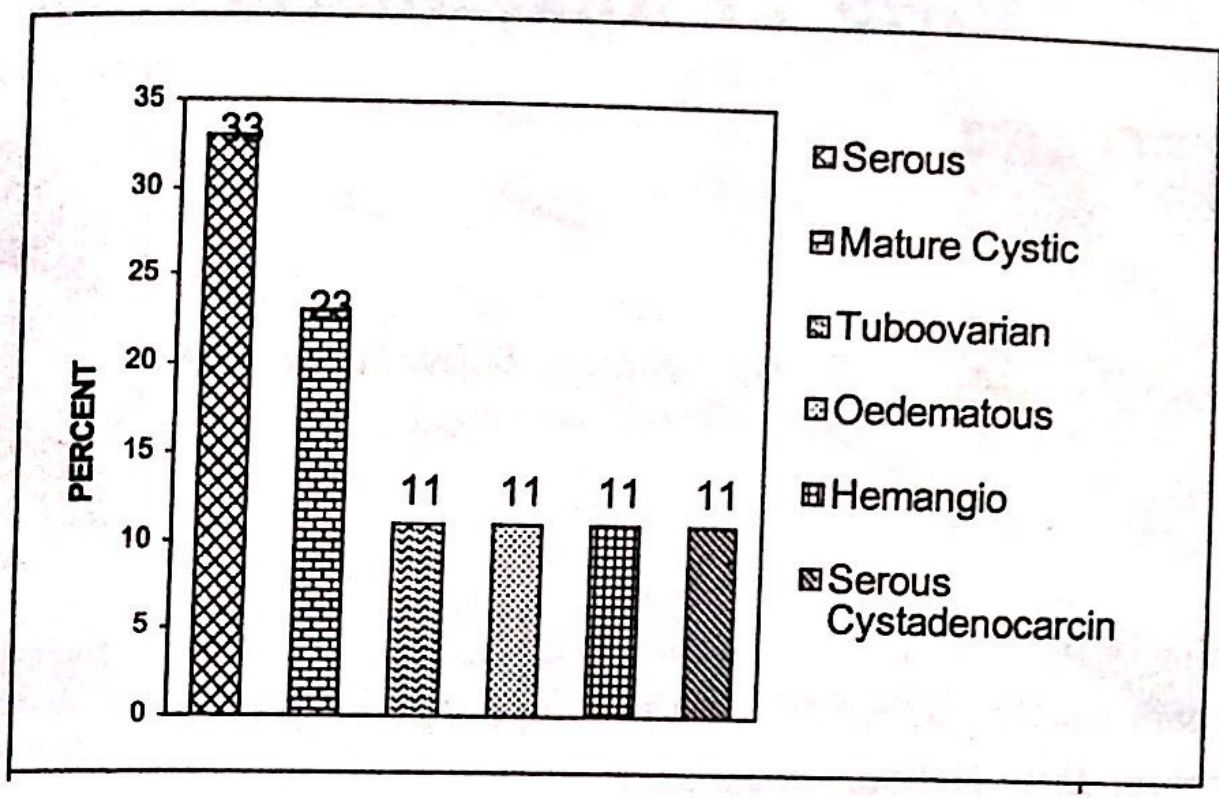

Central Nervous System (2)

Acute Cerebritis with Brain Abscess - 1

Meningioma (Chordoid) - 1

Eye (3)

Trauma - 1

Capillary Hemangioma - 1

Chronic Scleritis - 1

PIVD (23)

Degenerative Changes - All
Tonsils (30)

Tonsillar Hypertrophy with Follicular Hyperplasia - All

Liver (2)

Chronic Hepatitis - 1

Metastatic Adenocarcinima - 1

Spleen (3)

Rupture - All

Bone Marrow (1)

Hyperplastic Marrow

\section{Interns Joke Competition (First Prize)}

\section{A Husband's Moment of Realisation}

A woman's husband had been slipping in and out of a coma for several months, yet she stayed by his bedside every single day. When he came to, he motioned for her to come nearer.

As she sat by him, he said, "You know what? You have been with me all through the bad times. When I got fired, you were there to support me. When my business failed, you were there. When I got shot, you were by my side. When we lost the house, you gave me support. When my health started failing, you were still by mey side... You know what?"

"What dear?" She asked gently.

'T think you bring me bad luck." 